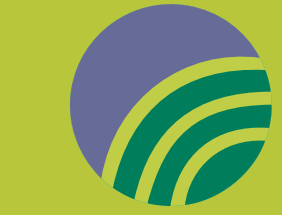

\title{
MRS hosts virtual programs to recognize global diversity awareness
}

\author{
mrs.org/diversity
}

$\mathrm{R}$ ecognizing that diversity drives innovation, excellence, and new discoveries, the Materials Research Society (MRS) hosted a number of virtual programs last October designed to advance diversity, equity, and inclusion in the materials community. These programs gave members of the materials community the opportunity to listen and learn, as well as engage in the difficult conversations needed in order to build a truly diverse and inclusive environment.

\section{Intersections of underrepresentation in materials science and engineering}

Poet Muriel Rukeyser wrote in 1968 , "What would happen if one woman told the truth about her life? The world would split open." Over 50 years later, at the MRS Women in Materials Science and Engineering working group webinar that explored real-life examples of bias and injustice against individuals from a diverse set of underrepresented groups, panelists shared their paths to their current careers. They spoke frankly about the ups and downs they have experienced, both pertaining to their membership in underrepresented groups as well as generally in the science, technology, engineering, and mathematics (STEM) fields. And listening to honest discussions remains enlightening.

Through their examples, Sossina M. Haile of Northwestern University (who was selected for the 2020 MRS David Turnbull Lectureship), Mónica LiraCantú of the Catalan Institute of Nanoscience and Nanotechnology, Jennifer Gerbi at the US Advanced Research Projects Agency-Energy (ARPA-E), and Carol Ellis-Terrell of Southwest Research Institute, with host Rebecca Anthony of Michigan State University, helped the audience reimagine how negative situations could have unfolded in a more positive way. The panelists provided strategies that can be implemented to create more accepting and inclusive environments.

A question came in from the audience about seeking support from other women. Gerbi said that subconscious gender bias occurs from everyone, including women, which she has experienced. On the other hand, Haile said that senior women faculty at various institutions had supported her. The new complication now that arises with the 
goal of diversifying the faculty, Haile said, "is that we are constantly secondguessing ourselves" about whether the candidate the search committee is choosing is actually the best for the department. 'It's not like taking a test where it's pretty clear what's the right answer and what's the wrong answer," she said. Being keenly aware of implicit bias, search committees work harder to ensure the best choice.

Some strategies search committees can consider are to look beyond the usual "criteria" of experiences and see what qualities candidates have that enabled them to overcome, for example, economic barriers that will also serve them well in the hiring position. The application forms can include the third pronoun (them/they) in order to let lgbtq + minorities know they are welcomed. When candidates turn down an offer, the hiring institution can stay in contact with them in case their situations change the next time a position is open.

And what about being the so-called "diversity hire"? How does one overcome impostor syndrome? Lira-Cantú told the story of one of her positions where she flew to the United States for a job and the woman sitting beside her said outright that she must have been hired because she's a woman. This had Lira-Cantú second-guessing her accomplishments to the point that when she arrived, she asked one of the people who had interviewed her, "Are you sure you made the right decision of hiring me?" Haile said there will always be people who will think someone is hired other than for their capabilities and to just disregard it. "The internalization of it — that's the hard piece," she said. Her advice is for women to be proud of their accomplishments. "Be proud of where you are," she said, "and that's what matters for yourself."

Ellis-Terrell's advice for researchers, when facing impostor syndrome, is to take another look at their resume to remind themselves of all their accomplishments. "We are in that position because we add value to it," she said.
When more women and women of color are serving on panels and committees, said Gerbi, the perception of a "diversity hire" will resolve itself.

In the meantime, the panelists also told stories about advocating for themselves. When they see they have been passed over for a job, promotion, or higher salary, to a male colleague with less experience or accomplishments, they raise the issue.

Gerbi said, "The playing field is not fair. And you have to let that not bother you. That bothered me for a while. So you really have to say, 'Okay, what $d o$ I have going for me?',

The webinar was sponsored by Taiyo Nippon Sanso Corporation and MilliporeSigma.

\section{Banish impostor syndrome}

Alaina Levine, President and Founder of Quantum Success Solutions, led a professional development webinar on strategies to implement to overcome the false sense of unworthiness known as “impostor syndrome." Levine's goal is to help the audience understand that it is a "definable, manageable problem that has unique borders to it, and that we can use our STEM education and training to actually solve." Levine pointed out that the "syndrome" is not reality and she covered 11 tactics that are available to separate the illusion from reality. She also emphasized that impostor syndrome is amplified for women and underrepresented minorities in STEM.

The first thing to note, she said, is that when we experience impostor syndrome, it means we are already advancing in our careers. Impostor syndrome sneaks in when we reach a turning point, either when we are looking for a position in a different type of institution such as industry when we have been in academia, or at a time when we apply for a number of jobs or grants that we do not receive. During the COVID-19 pandemic, where budgets have been tightened, researchers looking for their next job have to particularly guard themselves against this syndrome.

The initial line of defense is to know what emotions are tied to impostor syndrome. The list includes loss, anger, insecurity, frustration, and unvalued. Inaction can follow, letting impostor syndrome do its damage. Or, to experience and then overcome these emotions, one can take action such as transferring to another job, contacting another researcher for an appointment to talk, or applying for an MRS award. If, however, we falsely accuse ourselves of being unqualified, another tactic, Levine said, is to collect data that include our record of achievements, skills, problems we have solved, and our characteristics and compare these data to the job functions and responsibilities. In this way, we separate the illusion from reality, she said.

The webinar was sponsored by Taiyo Nippon Sanso Corporation.

\section{For more information}

The diversity page of the MRS website includes links to the full webinars as well as a webinar about unconscious bias and an interview with Massachusetts Institute of Technology and Harvard University Fellow Hugo Caicedo about challenges and obstacles black scientists face in STEM. The site also includes links to a series of articles MRS Bulletin recently published on Diversity and Inclusion issues facing underrepresented minorities within the materials community. MRS has a number of other programs and activities as well, including a mentoring program to increase the enthusiasm of underrepresented racial and ethnic minority (UREM) and female students to pursue advanced degrees and careers in materials science and engineering. MRS also launched a UREM Student Science Writing Program which is made possible through a generous donation by long-time dedicated MRS member and volunteer Steven C. Moss (see the article in this issue). For more information, access www.mrs.org/diversity. 